\title{
Molecular Epidemiological Survey of Rotaviruses in Sewage by Reverse Transcriptase Seminested PCR and Restriction Fragment Length Polymorphism Assay
}

\author{
E. DUBOIS,${ }^{1 *}$ F. LE GUYADER, ${ }^{1}$ L. HAUGARREAU,${ }^{1}$ H. KOPECKA, ${ }^{2}$ \\ M. CORMIER, ${ }^{3}$ AND M. POMMEPUY ${ }^{1}$ \\ Laboratoire de Microbiologie, Institut Français de Recherche pour l'Exploitation de la Mer, Nantes, ${ }^{1}$ \\ Unité de Virologie Moléculaire, Institut Pasteur, Paris, ${ }^{2}$ and Laboratoire de Microbiologie \\ Pharmaceutique, UER Médicales et Pharmaceutiques, Rennes, ${ }^{3}$ France
}

Received 27 August 1996/Accepted 20 February 1997

\begin{abstract}
Rotavirus double-stranded RNA was detected directly in sewage treatment plant samples over a 1-year period by reverse transcription followed by PCR amplification of the VP7 gene and Southern blot hybridization. The presence of naturally occurring rotaviruses was demonstrated in $42 \%$ of raw sewage samples and in $67 \%$ of treated effluent samples. Amplified viral sequences were analyzed by restriction enzymes. Ten different restriction profiles were characterized, most of which were found in treated effluent samples. A mixture of restriction profiles was observed in $\mathbf{7 5 \%}$ of contaminated effluent samples. The profiles were compared with those obtained from human rotavirus isolates involved in infections in children from the same area (six different profiles were detected). Five identical viral sequences were detected in both environmental and clinical samples. Restriction profiles were also compared to profiles from known genomic sequences of human and animal viruses. Both human and animal origins of rotavirus contamination of water seemed likely.
\end{abstract}

Rotaviruses are responsible for severe gastroenteritis in humans and animals (14). After replicating in the gastrointestinal tract, these viruses are excreted and may be dispersed in environmental waters $(3,19)$. Rotaviruses have been implicated in water-borne gastroenteritis outbreaks in many countries (for a review, see reference 1 ). The stability of human rotaviruses in environmental water $(22,30)$ and their resistance to physicochemical treatment processes in sewage treatment plants may facilitate their transmission $(24,27)$.

Enzymatic amplification and hybridization have been described for detection of rotaviruses in environmental samples $(5,9,28,31)$. We recently reported the efficiency of reverse transcriptase (RT)-seminested PCR in detecting rotavirus VP7 gene sequences in naturally contaminated shellfish and surface waters $(18,23)$.

In the present study, rotavirus contamination was detected in raw sewage and treated effluent samples by RT-seminested PCR without using a preliminary concentration step. The viral sequences detected were characterized by analysis of the restriction fragment length polymorphism (RFLP) of the amplification products to detect the strain diversity in the environmental samples. The RFLP assay was previously described for rapid comparison of a large number of virus isolates, and a relationship was established between some restriction sites on the VP7 gene and the serotype (G types) or origin of the virus (human or animal) $(11,29)$. The identity between RFLP profiles was used to establish a correlation between contamination in water samples and the viral sequences obtained from clinical samples. To confirm the origin of the characterized rotavirus sequences, similarities to the RFLP profiles of known rotavirus sequences from the databases were compared.

\footnotetext{
* Corresponding author. Mailing address: Laboratoire de Microbiologie, IFREMER, B.P. 21105, 44311 Nantes Cedex 03, France. Phone: (33) 2403740 52. Fax: (33) 240374073.
}

\section{MATERIALS AND METHODS}

Virus strain. The simian rotavirus strain SA11 was grown and the titer in MA104 cells was determined by an immunofluorescence method (determination of the number of focus-forming units [FFU]), as previously described (2).

Sewage samples. Raw sewage and treated effluent samples (the sewage treatment plant used physicochemical methods: settling and aluminum hydroxide flocculation treatment) were collected monthly over a 1-year period (1993) in western France. To minimize the effects of diurnal variations, samples were collected between 11 a.m. and 1 p.m. Sewage and effluent samples were transported to the laboratory on ice and immediately frozen at $-20^{\circ} \mathrm{C}$ until used.

Fecal specimens. Stool specimens were collected during the same year from children with acute gastroenteritis admitted to the hospital nearest to the sewage treatment plant. Forty-three stool samples positive for rotavirus antigen by the latex agglutination method (Slidex Rota-Kit 2; BioMérieux) were stored at $-20^{\circ} \mathrm{C}$ until analyzed.

Sample preparation. Nucleic acid extracts were obtained directly from $410 \mu \mathrm{l}$ of raw sewage and treated effluent samples or from $410 \mu \mathrm{l}$ of a $50 \%(\mathrm{wt} / \mathrm{vol})$ stool suspension in diethyl pyrocarbonate-treated distilled sterile water (DEPC water) (25). For each experiment, DEPC water was used as a negative control. Samples were treated with a mixture of $0.1 \mathrm{M}$ Tris- $\mathrm{HCl}(\mathrm{pH} 7.5), 5 \mathrm{mM}$ EDTA, 1\% sodium dodecyl sulfate, and $200 \mu \mathrm{g}$ of proteinase K (Sigma) per ml for $1 \mathrm{~h}$ at $56^{\circ} \mathrm{C}$ and then extracted with an equal volume of phenol-chloroform-isoamyl alcohol $(25: 24: 1)$. Nucleic acids were recovered by ethanol precipitation and dissolved in $50 \mu$ l of DEPC water. Double-stranded RNA (dsRNA) was purified by adsorption onto granular cellulose (CC41; Whatman) and eluted in $25 \mu \mathrm{l}$ of DEPC water under conditions previously described (18). The presence of vira dsRNAs in stool extracts was controlled by electrophoresis in a $9 \%$ polyacrylamide gel and ethidium bromide staining.

Primers and probe. Primers Beg9, R2, and R3 were previously selected to amplify sequences in the VP7 gene of group A rotaviruses $(8,12)$. The oligoprobe $(\mathrm{Rp})$ used in Southern blot hybridization corresponded to a conserved region located within the amplification product (18).

Enzymatic amplification of dsRNA. (i) RT. Two microliters of extracted nucleic acids was added to $2.6 \mu \mathrm{l}$ of the denaturation mixture consisting of $10 \mu \mathrm{M}$ downstream primer Beg9 and $10 \mathrm{mM}$ methylmercuric hydroxide. After incubation at room temperature for $5 \mathrm{~min}$, the mixture was supplemented with $50 \mathrm{mM}$ Tris-HCl (pH 8.3), $75 \mathrm{mM} \mathrm{KCl,} 60 \mathrm{mM}$ dithiothreitol, $3 \mathrm{mM} \mathrm{MgCl}_{2}, 400 \mu \mathrm{M}$ deoxynucleoside triphosphates, $5 \mu \mathrm{M}$ Beg9 primer, $10 \mathrm{U}$ of RNase BlockI ribonuclease inhibitor (Stratagene), and $10 \mathrm{U}$ of Moloney murine leukemia virus RT (Stratagene) to obtain a final volume of $10 \mu \mathrm{l}$ and incubated at $37^{\circ} \mathrm{C}$ for $45 \mathrm{~min}$

(ii) PCR. A 40- $\mu$ l volume of PCR mix was added to the total RT product to yield $50 \mu \mathrm{l}$ of a final mixture containing $10 \mathrm{mM}$ Tris- $\mathrm{HCl}(\mathrm{pH} 8.3), 50 \mathrm{mM} \mathrm{KCl}$, $2.5 \mathrm{MgCl}_{2}, 200 \mu \mathrm{M}$ deoxynucleoside triphosphates, $1 \mu \mathrm{M}$ (each) downstream (Beg9) and upstream (R2) primers, and $1 \mathrm{U}$ of Taq DNA polymerase (PerkinElmer Cetus Corp.). The cycling conditions were as follows: initial heat denaturation at $94^{\circ} \mathrm{C}$ for $1 \mathrm{~min} ; 30$ cycles of template denaturation at $94^{\circ} \mathrm{C}$ for $30 \mathrm{~s}$, 

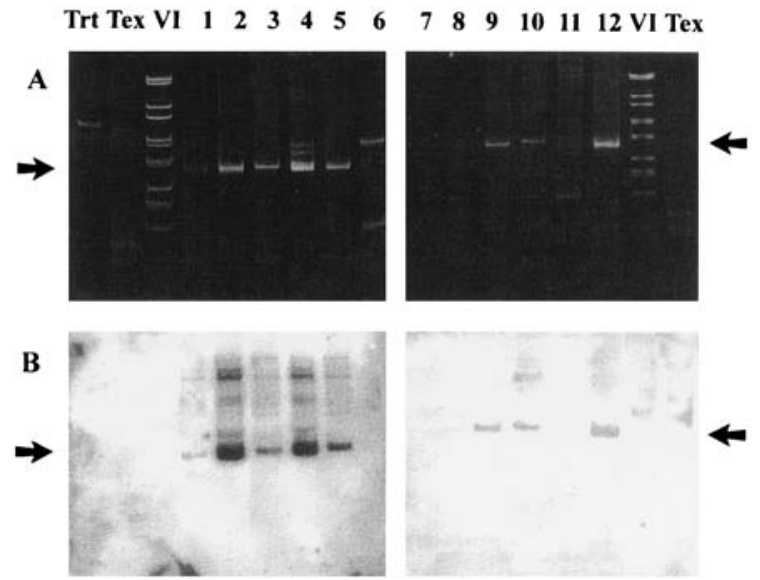

FIG. 1. Rotavirus dsRNA detection in sewage treatment plant samples during a 1-year period. Polyacrylamide gel electrophoresis of RT-seminested PCR products from treated effluent samples (A) and corresponding Southern blot hybridization (B). Lanes 1 to 12: samples from January to December, respectively; Tex, negative control for nucleic acid extraction; Trt, negative control for RT-seminested PCR; VI, DNA molecular weight marker VI (Boehringer Mannheim). The arrows indicate signals with the expected size of $342 \mathrm{bp}$

primer annealing at $50^{\circ} \mathrm{C}$ for $30 \mathrm{~s}$, and primer extension at $72^{\circ} \mathrm{C}$ for $30 \mathrm{~s}$; and final extension at $72^{\circ} \mathrm{C}$ for $3 \mathrm{~min}$. Stool extracts were analyzed by RT-PCR under the same conditions, except that primer R3 was used instead of Beg9 in the RT reaction and primers $\mathrm{R} 3$ and $\mathrm{R} 2$ were used in a single amplification reaction.

(iii) Seminested PCR. Seminested PCR was performed with $2 \mu \mathrm{l}$ of the amplified product used as a template in $23 \mu \mathrm{l}$ of the same reaction mixture as that used for the first PCR, except for the primer set, which was composed of internal (R3) and upstream (R2) primers. Negative controls (DEPC water used as samples) were included in each amplification series. Amplified products, 392 and $342 \mathrm{bp}$ in length after RT-PCR and seminested PCR, respectively, were detected by $9 \%$ polyacrylamide gel electrophoresis and ethidium bromide staining.

Hybridization. PCR products were transferred from gel by electroblotting onto a positively charged membrane (Boehringer) and were hybridized with the oligoprobe $\mathrm{Rp} 3^{\prime}$ end labeled with digoxigenin-dUTP (DIG oligonucleotide tailing kit; Boehringer). Hybrids were detected by the chemiluminescent detection method (DIG luminescent detection kit; Boehringer).

Detection of RT-PCR inhibitors. Simian rotavirus SA11 dsRNA was extracted from $500 \mu \mathrm{l}$ of infected tissue culture $\left(1.8 \times 10^{4} \mathrm{FFU} / \mathrm{ml}\right)$, as previously described. This viral RNA extract was diluted (1:10) in the sewage RNA extract to be tested, and the mixture was analyzed by RT-seminested PCR. The amount of viral RNA added was adjusted so as to be detected only after seminested PCR. The presence or absence of amplified sequences was checked by polyacrylamide gel electrophoresis and ethidium bromide staining.

Restriction endonuclease analysis. Three different protocols were used for restriction endonuclease analysis, depending on the purity of the amplified products.

(i) Protocol i. If only one band of the expected size was visible in the polyacrylamide gel, the amplified products were digested in separate reactions with either of the AluI, RsaI, Sau3AI, or TaqI restriction endonucleases (Eurogentec). Briefly, $18 \mu \mathrm{l}$ of PCR product was digested for $2 \mathrm{~h}$ with $10 \mathrm{U}$ of restriction endonuclease, under conditions recommended for each restriction enzyme. Restriction products were separated by electrophoresis in $9 \%$ polyacrylamide gel for sensitive, quick screening or in $2.5 \%$ NuSieve GTG agarose gel (FMC BioProducts) for size estimation.

(ii) Protocol ii. If spurious nonspecific bands interfered with analysis after electrophoresis of PCR products and/or if the amplicon gave a weak signal by ethidium bromide staining, the amplified products of the expected size were purified from the polyacrylamide gel (25) and used for further amplification to increase the number of copies before digestion (protocol i). A negative control was run throughout the purification and amplification steps.

(iii) Protocol iii. Different viral sequences were sometimes coamplified. The DNA copies were then cleaved by the previously described restriction endonucleases or with a different restriction endonuclease-either DraI, SspI (Eurogentec), or NlaIII (New England Biolabs). The undigested sequences were purified by electrophoresis before RFLP analysis (protocol ii). If a mixture of sequences was still observed, the reaction was repeated.

RFLP profiles in data banks. Ninety-three rotavirus VP7 gene sequences deposited in the GenBank and EMBL nucleotide sequence databases were selected for their ability to hybridize with the primers used in the RT-seminested PCR (minimum of $80 \%$ homology with primers Beg9, R2, and R3 was required).
Computer analysis was used to locate restriction sites in sequences between nucleotide 72 (the first nucleotide after primer R3) and nucleotide 375 (the las nucleotide before primer R2) (6). The fragment sizes generated by AluI, RsaI, Sau3AI, and TaqI restriction endonucleases were calculated and compared with our experimental results. The degree of similarity (DS) between the experimental RFLP profiles and the profiles deduced from the databases was determined by the formula of Kristiansen et al. (16): DS $=100 \%-(N d \times 100) / N s$, where $N s$ is the total number of bands shared by the two profiles and $N d$ is the number of bands not shared by both profiles (with allowance for a $10 \%$ experimental error in fragment size estimation).

\section{RESULTS}

Sensitivity study. We first determined the sensitivity of our detection method by performing assays with purified RNA extracts obtained from dilutions of known concentrations of rotavirus SA11 in DEPC water. A band of the correct size was observed after RT-PCR for the sample seeded with $1.8 \times 10^{4}$ FFU/ml; seminested PCR increased sensitivity to $1.8 \times 10^{3}$ FFU/ml (data not shown).

Viral RNA detection in environmental samples. One treated effluent sample collected in December was positive by direct analysis (data not shown). After purification of nucleic acids onto granular cellulose, four raw sewage samples and nine effluent samples (Fig. 1A) were positive by RT-seminested PCR. No amplified sequences were detected after RT-PCR (data not shown). These results were confirmed by hybridization with the oligoprobe (Fig. 1B). After hybridization, the raw sewage sample from March was positive (Table 1). Raw sewage and treated effluent samples were both found to be contaminated by rotavirus at three sampling times: January, March, and December. In June and November, no dsRNA was detected. For the other months, either sewage or effluent samples were positive (Table 1).

The absence of inhibitors in nucleic acid extracts was controlled for each negative sample by introduction of viral RNA before further amplification (Table 1). Inhibitors were detected in two raw sewage samples (February and June).

RFLP analysis of amplicons obtained from environmental samples. The eight amplified viral products obtained from treated effluent samples (Table 1) were analyzed by RFLP

TABLE 1. Rotavirus detection in raw sewage and treated effluent samples over a 1-year period, and checking for amplification reaction inhibitors

\begin{tabular}{|c|c|c|c|c|}
\hline \multirow{3}{*}{$\begin{array}{l}\text { Sampling date } \\
\text { (mo/day/yr) }\end{array}$} & \multicolumn{4}{|c|}{ Result for: } \\
\hline & \multicolumn{2}{|c|}{ Treated effluents } & \multicolumn{2}{|c|}{ Raw sewage } \\
\hline & Virus $^{a}$ & Inhibitors $^{b}$ & Virus $^{a}$ & Inhibitors ${ }^{b}$ \\
\hline $01 / 24 / 93$ & + & $\mathrm{ND}^{c}$ & + & ND \\
\hline $02 / 09 / 93$ & + & ND & - & + \\
\hline $03 / 09 / 93$ & + & ND & + & ND \\
\hline $04 / 07 / 93$ & + & ND & - & - \\
\hline $05 / 24 / 93$ & + & ND & - & - \\
\hline $06 / 21 / 93$ & - & - & - & + \\
\hline $07 / 19 / 93$ & - & - & + & ND \\
\hline $08 / 17 / 93$ & - & - & + & ND \\
\hline $09 / 16 / 93$ & + & ND & - & - \\
\hline $10 / 14 / 93$ & + & ND & - & - \\
\hline $11 / 15 / 93$ & - & - & - & - \\
\hline $12 / 13 / 93$ & + & ND & + & ND \\
\hline
\end{tabular}

${ }^{a}$ The rotavirus VP7 gene was searched for in extracts by RT-seminested PCR and hybridization. + and - , positive and negative samples, respectively, after analysis.

${ }^{b}$ Inhibitor presence $(+)$ or absence $(-)$ in purified nucleic acid extracts was checked only in negative samples by introduction of viral dsRNA before a new amplification.

${ }^{c} \mathrm{ND}$, not done. 


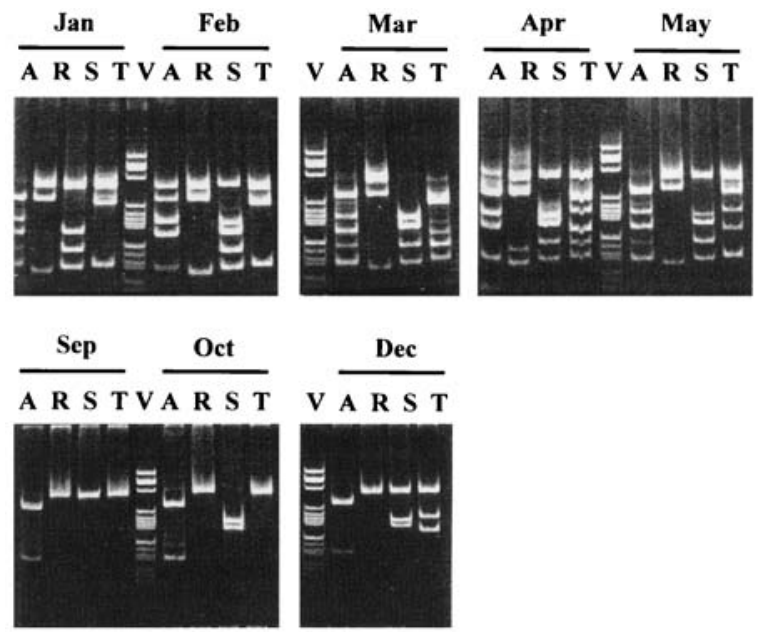

FIG. 2. Viral sequence diversity in amplified products obtained from treated effluent samples. Direct viral copies corresponding to RT-seminested PCR on nucleic acid extracts were purified from gel electrophoresis and amplified another time with R2 and R3 primers before the PCR products were cleaved by $A l u \mathrm{I}$ (lane A), RsaI (lane R), Sau3AI (lane S), and TaqI (lane T) restriction enzymes. Digestion products were analyzed by polyacrylamide gel electrophoresis, stained with ethidium bromide, and visualized under UV light. Lane V, DNA molecular weight marker V (Boehringer Mannheim).

assay. Six PCR products corresponding to samples from January to May and from December contained several sequences characterized by mixed RFLP profiles, whereas unique profiles were obtained from the September and October samples (Fig. $2)$. The analysis of these combinations showed two to six different profiles for one amplicon (Fig. 3 and 4). A total of eight different RFLP profiles were characterized (profiles A to $\mathrm{H}$ ) (Fig. 4).

Four amplicons from raw sewage samples were analyzed by the same approach. The amplified product from the March sample contained insufficient DNA for RFLP analysis. Amplicons displayed four unique RFLP profiles (A, E, I, and J) (Fig. 4). Profile A detected in raw sewage samples from January was identical to that observed in treated effluent samples from January to May (Fig. 4). Profile E observed in sewage from July was identical to one profile characterized in effluent samples from April (Fig. 4).

RFLP analysis of human rotavirus sequences. Amplified products from clinical samples (40 samples) were analyzed by

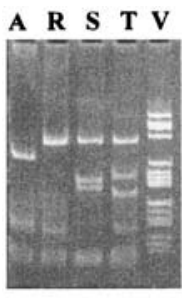

Profile B/F

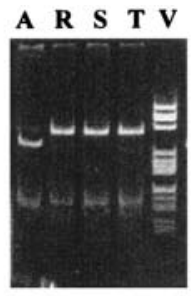

Profile B

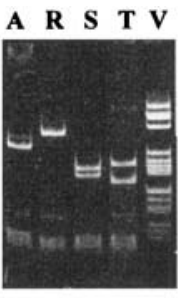

Profile F
FIG. 3. RFLP analysis of treated effluent samples collected in December. Profile B/F, a mixture of profiles, was obtained from the RT-seminested PCR amplicon by direct RFLP assay. Profiles B and F were obtained after purification of undigested sequences by restriction enzymes Sau3AI and DraI, respectively. PCR products were cleaved by AluI (lane A), RsaI (lane R), Sau3AI (lane S), and TaqI (lane T) restriction enzymes. Digestion products were analyzed by polyacrylamide gel electrophoresis, stained with ethidium bromide, and visualized under UV light. Lane V, DNA molecular weight marker V (Boehringer Mannheim).
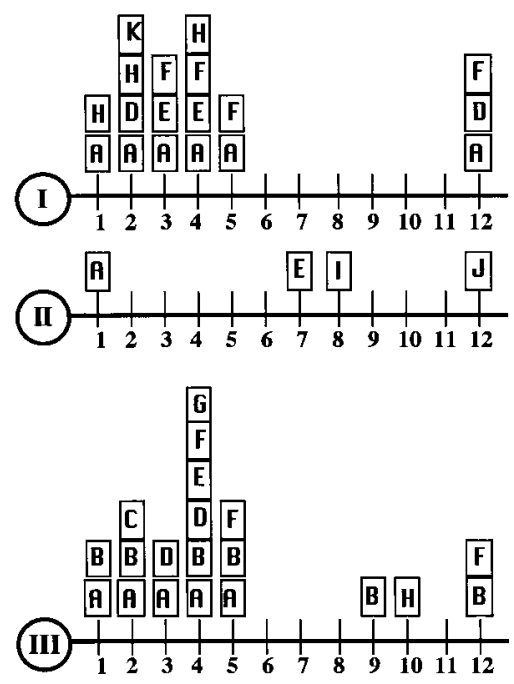

FIG. 4. Temporal distribution of RFLP profiles (A to K) isolated from clinical (I), raw sewage (II), and treated effluent (III) samples in western France in 1993. Numbers 1 to 12 correspond to January to December, respectively.

the same protocol. Six different RFLP profiles were generated (A, D, E, F, H, and K), and two to four RFLP profiles were characterized monthly (Fig. 4). No mixture of RFLP profiles was observed in any stool sample, and no mixture of electropherotypes characterized by more than 11 dsRNA segments was detected (data not shown).

Environmental and clinical RFLP profile comparison. The 6 RFLP profiles of human origin were compared with the 10 profiles detected in raw sewage or treated effluent samples (Fig. 4). Two RFLP profiles from raw sewage (I and J) and three RFLP profiles from treated effluent samples $(B, C$, and $\mathrm{G})$ had no homology with those isolated in human stools. However, three profiles (D, F, and $\mathrm{H}$ ) were identical to treated effluent profiles, and two RFLP profiles characterized in human stools (A and E) were identical to those found in both raw sewage and treated effluent samples. Profile K was only obtained with clinical samples. Overall, 11 different RFLP profiles were characterized (Fig. 5).

Similarities to rotavirus sequences deposited in databases. Forty-nine distinct RFLP profile types were deduced from 93 human and animal rotavirus sequences. Among the RFLP profiles established from the databases, only two were common to strains from different species: one from bovine, porcine, and simian species and the other from human and simian species (data not shown).

We compared the 11 RFLP profiles observed in our experiments with those estimated from group A rotavirus sequences deposited in databases (Table 2). The profiles found in human stool and sewage treatment plant samples (A, D, E, F, and H) showed a similarity to RFLP profiles from human rotavirus strains with the G1, G2, or G4 serotype (Table 2). Other similarities were found between profile $\mathrm{H}$ and the RFLP profiles from two porcine rotavirus strains, also of the G2 serotype. Profile K, characterized only in human stool samples, had no homologous profile in the databases but showed partial similarities to one profile common to six human strains with the G1 serotype.

RFLP profiles $G$ and I, characterized from both sewage and effluent samples, showed neither homology to local human strains nor any similarities to profiles from database sequences, although partial similarities to animal and human strains were 


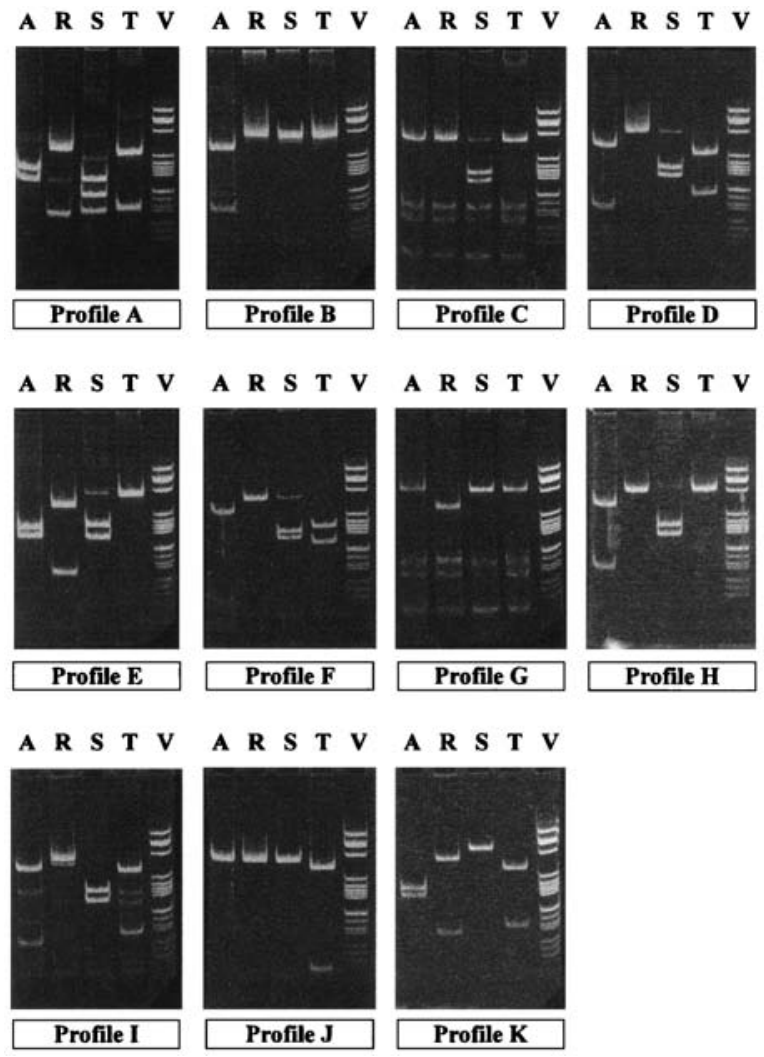

FIG. 5. RFLP profiles and the corresponding estimated size of the amplified product. After digestion by AluI (lane A), RsaI (lane R), Sau3AI (lane S), and TaqI (lane T), DNA fragments were separated by polyacrylamide gel electrophoresis and stained with ethidium bromide. Lane V, DNA molecular weight marker V (Boehringer Mannheim). The profiles shown were found in raw sewage samples (I and J), treated effluent samples (B, C, and G), and human stool samples (A, D, E, F, H, and K).

found. Profile $G$ displayed a homology with the profile from a bovine rotavirus with a G8 serotype. RFLP profile I showed partial similarities to three RFLP profiles: one from porcine rotavirus with a G11 serotype, one common to two porcine rotavirus strains with a $\mathrm{G} 2$ serotype and an unknown serotype, and one from human rotavirus with a G2 serotype. Complete homologies were observed for the other profiles obtained from sewage treatment plant samples (Table 2). Profile B from effluent samples was similar to one human strain and one simian rotavirus strain. Profile $\mathbf{J}$ found in a sewage sample was similar to profiles from different virus strains with different serotypes from animal species. Only one human rotavirus with a G8 serotype showed a profile similar to profile C.

\section{DISCUSSION}

The present study demonstrates the efficiency of RT-seminested PCR and RFLP analysis in characterizing rotavirus contamination of environmental samples and the usefulness of these techniques for studying epidemiological relationships between strains involved in human infections and those contaminating waters.

RT-seminested PCR was chosen for its specificity and sensitivity in detecting a low viral load in environmental samples $(15,17,18,23)$. In our study, analysis of highly contaminated water samples did not require a viral concentration. The inhibitors present in sewage extracts were partially eliminated by nucleic acid purification onto granular cellulose. This purification step has already been used successfully for detection of rotavirus dsRNA in shellfish samples (18). Although inhibitors were still detected in two raw sewage samples, no additional purification step was performed for these samples in order to avoid possible loss of viral nucleic acids. The use of several extraction procedures did not solve this problem. Subsequent to completion of the laboratory work described here, a method for efficient extraction and purification of rotavirus RNA from sewage samples was described, which also provided increased detection sensitivity (9).

Raw sewage and secondary effluent samples were found to be contaminated by rotaviruses (Table 1). These results confirmed the persistence of viral contamination after water treatment $(24,26)$. Considering that our detection sensitivity was about $2 \times 10^{3} \mathrm{FFU} / \mathrm{ml}$, the positive water samples appear to contain large numbers of viruses. Geometric means of rotavirus levels previously determined in raw sewage ranged from 10 to $2.2 \mathrm{FFU} /$ liter $(13,19)$. The greatest concentration measured was $1 \times 410^{4} \mathrm{FFU} /$ liter in Barcelona raw sewage (3). However, because the ratio of virions to infectious units is not known in environmental samples and because RT-PCR detects RNA from infectious and noninfectious particles, it is difficult to compare our data with previously published results. The different RFLP profiles detected in the sewage treatment plant samples showed a large diversity of virus sequences. RFLP analysis was difficult with samples contaminated simultaneously by several rotavirus strains. The use of restriction endonucleases to cleave some, but not all, rotavirus sequences provided different profiles from a single amplicon (Fig. 3). Each RFLP profile belonged to rotavirus sequences, since all of the purified sequences hybridized with the Rp probe (data not shown). This diversity is attributable to the presence of different rotavirus strains and/or to point mutations in the restriction sites.

A more frequent contamination of treated effluent samples (8 positives among 12 samples) than raw sewage samples (5 positives among 12 samples) was found (Table 1), and fewer RFLP profiles were also observed in raw sewage samples (four different RFLP profiles), compared to those obtained from treated effluent samples (seven different RFLP profiles) (Fig. 4). Moreover, most treated effluent samples contained a mixture of profiles, whereas only a single profile was found in raw sewage samples. The reason for the lower frequency of contamination in raw sewage than treated effluent samples is not clear. One possibility is that the greater concentration of inhibitors in raw sewage samples was not completely eliminated during purification, thereby reducing the efficiency of the amplification step (Table 1). Inhibitor levels could in fact be lower in effluent samples after water treatment. The temporal heterogeneity of raw sewage samples might also be a contributing factor. The lower diversity of virus sequences obtained from sewage samples may have been due to the more heterogeneous composition of raw sewage compared to that of treated effluent samples. However, there may also have been a mixture of viruses in raw sewage samples, with only the most represented sequence being characterized. Studies with competitive PCR have shown that the presence of one template at a 100 -foldhigher amount almost completely outcompetes amplification from the underrepresented template (10). Consequently, in treated effluent samples, more different viral sequences could be present at the same amount and thus simultaneously amplified.

The diversity of RFLP profiles obtained from treated effluent samples was greater, especially during the winter and spring months (Fig. 2 and 4). It is likely that the distribution 
TABLE 2. Homologies between experimental RFLP profiles and RFLP profiles in databases

\begin{tabular}{|c|c|c|c|c|c|c|c|c|c|c|c|c|c|}
\hline & & & result & & & & & & & Database result ${ }^{a}$ & & & \\
\hline Profile & & Fragm & size (bp) & & DS $(\%)$ & & Fragme & size (bp) & & Strain (s) or & VP7 (G) & Orioin & Accession \\
\hline & $A l u \mathrm{I}$ & RsaI & Sau3AI & $\operatorname{Taq} \mathrm{I}$ & $50(10)$ & $A l u \mathrm{I}$ & $R s a \mathrm{I}$ & Sau3AI & $T a q \mathrm{I}$ & te (i) & serotype & & \\
\hline A & 180 & 255 & 148 & 255 & 100 & 196 & 268 & 163 & 263 & 421 (i) & G1 & Human & D16326 \\
\hline & 141 & 77 & 104 & 85 & & 146 & 74 & 104 & 79 & 80 (i) & G1 & Human & D16325 \\
\hline & & & 80 & & & & & 75 & & A91A (s) & G1 & Human & M93006 \\
\hline B & 266 & 342 & 342 & 342 & 100 & 263 & 342 & 342 & 342 & HCRS (s) & G3 & Human & L21666 \\
\hline & 80 & & & & & 79 & & & & $\mathrm{NS}^{d}$ & & Simian & M21650 \\
\hline $\mathrm{C}$ & 339 & 339 & 180 & 339 & 100 & 342 & 342 & 179 & 342 & B37 (s) & G8 & Human & J04334 \\
\hline & & & 161 & & & & & 163 & & & & & \\
\hline $\mathrm{D}$ & 265 & 342 & 176 & 228 & 100 & 263 & 342 & 181 & 233 & Australia/5/77 (s) & $\mathrm{G} 2$ & Human & X00572 \\
\hline & 80 & & 159 & 117 & & 79 & & 161 & 109 & & & & \\
\hline $\mathrm{E}$ & 200 & 256 & 180 & 346 & 100 & 196 & 268 & 179 & 342 & K3 (i) & G1 & Human & D16317 \\
\hline & 144 & 75 & 150 & & & 146 & 74 & 163 & & K17 (i) & G1 & Human & D16320 \\
\hline & & & & & & & & & & K18 (i) & G1 & Human & D16319 \\
\hline & & & & & & & & & & $\mathrm{C} 1(\mathrm{~s})$ & G1 & Human & D17717 \\
\hline & & & & & & & & & & $\mathrm{C} 2(\mathrm{~s})$ & G1 & Human & D17718 \\
\hline & & & & & & & & & & $\mathrm{C} 4(\mathrm{~s})$ & G1 & Human & D17720 \\
\hline & & & & & & & & & & TE1 (s) & G1 & Human & D17721 \\
\hline & & & & & & & & & & TE2 (s) & G1 & Human & D17722 \\
\hline & & & & & & & & & & TE3 (s) & G1 & Human & D17723 \\
\hline $\mathrm{F}$ & 255 & 344 & 180 & 199 & 100 & 263 & 342 & 179 & 202 & NS & G4 & Human & A01321 \\
\hline & 57 & & 155 & 141 & & 43 & & 163 & 140 & St. Thomas 3 (s) & G4 & Human & $\mathrm{X} 13603$ \\
\hline & $<50$ & & & & & 32 & & & & PV5249 (s) & G4 & Human & M86490 \\
\hline G & 347 & 241 & 347 & 347 & 73 & 342 & 241 & 342 & 209 & A5 (s) & G8 & Bovine & D01054 \\
\hline & & 107 & & & & & 101 & & 133 & & & & \\
\hline $\mathrm{H}$ & 262 & 350 & 178 & 350 & 100 & 263 & 342 & 179 & 342 & NS & $\mathrm{G} 2$ & Human & M11164 \\
\hline & 80 & & 162 & & & 79 & & 163 & & M48 (s) & $\mathrm{G} 2$ & Human & L11605 \\
\hline & & & & & 100 & 266 & 342 & 179 & 342 & $\mathrm{CC} 117$ (s) & NS & Porcine & L35056 \\
\hline & & & & & & 76 & & 163 & & $\mathrm{C} 134(\mathrm{~s})$ & $\mathrm{G} 2$ & Porcine & L35058 \\
\hline I & 281 & 344 & 184 & 268 & 77 & 342 & 342 & 179 & 271 & A253 (i) & G11 & Porcine & L24163 \\
\hline & 70 & & 162 & 75 & & & & 163 & 71 & & & & \\
\hline & & & & & 77 & 263 & 342 & 179 & 342 & NS & G2 & Human & M11164 \\
\hline & & & & & & 79 & & 163 & & M48 (s) & G2 & Human & L11605 \\
\hline & & & & & 77 & 266 & 342 & 179 & 342 & CC117 (s) & NS & Porcine & L35056 \\
\hline & & & & & & 76 & & 163 & & $\mathrm{C} 134(\mathrm{~s})$ & G2 & Porcine & L35058 \\
\hline $\mathrm{J}$ & 342 & 342 & 342 & 298 & 100 & 342 & 342 & 342 & 301 & C60 (i) & G1 & Porcine & L24164 \\
\hline & & & & 50 & & & & & 41 & NS & G6 & Bovine & M63266 \\
\hline & & & & & & & & & & SA11 (s) & G3 & Simian & J02354 \\
\hline & & & & & & & & & & & & & $\begin{array}{l}\text { K02028 } \\
\text { V01546 }\end{array}$ \\
\hline & & & & & & & & & & & & & \\
\hline K & $\begin{array}{l}187 \\
147\end{array}$ & $\begin{array}{r}275 \\
80\end{array}$ & 350 & $\begin{array}{r}250 \\
90\end{array}$ & 80 & $\begin{array}{l}196 \\
146\end{array}$ & $\begin{array}{r}268 \\
74\end{array}$ & $\begin{array}{l}179 \\
163\end{array}$ & $\begin{array}{r}263 \\
79\end{array}$ & Wa (s) & G1 & Human & $\begin{array}{l}\text { M21843 } \\
\text { K02033 }\end{array}$ \\
\hline & & & & & & & & & & $\mathrm{KU}(\mathrm{s})$ & G1 & Human & D16343 \\
\hline & & & & & & & & & & $\mathrm{K} 1$ (s) & G1 & Human & D16324 \\
\hline & & & & & & & & & & $\mathrm{K} 2(\mathrm{~s})$ & G1 & Human & D16323 \\
\hline & & & & & & & & & & K8 (s) & G1 & Human & D16344 \\
\hline & & & & & & & & & & RV-4 (s) & G1 & Human & M64666 \\
\hline
\end{tabular}

${ }^{a}$ Nucleotide sequences appear in the EMBL and GenBank databases under the accession numbers indicated.

${ }^{b}$ The fragment sizes reported were calculated after electrophoresis on low-melting-point agarose, as described in Materials and Methods. An experimental error estimated at $10 \%$ of fragment size was observed.

${ }^{c}$ RFLP profiles were calculated according to the localization sites on the VP7 gene sequences.

${ }^{d} \mathrm{NS}$, not specified.

and variations of viral sequences at that time were due to the increase in rotavirus infections involving different strains. Such seasonal variations in infection have been noted in developed countries, whereas rotavirus infections occur year-round in tropical climates (4). Moreover, studies of rotavirus outbreaks in several hospitals have shown that several strains (characterized by serotyping and electropherotyping) cause infections in children $(7,21)$. Previous studies have also indicated that ro- 
tavirus levels in sewage are generally higher during winter and spring (13), corresponding to seasonal variations of rotaviral diarrhea in the population (19). Although rotaviruses with different genotypes have been obtained from different sewage samples (9), no previous reports have described a diversity of rotavirus sequences from a single environmental sample. In our experiments, variations in human virus RFLP analysis were observed during the same season (Fig. 4). Most profiles characterized in the sewage treatment plant samples were similar to those found in human specimens for the part of the VP7 gene analyzed (303 out of $1,062 \mathrm{bp}$ ). The identity of the strains could be established by sequencing and/or studying another gene. However, the RFLP assay seems to be a powerful method for evaluating the diversity of viral strains in one sample (Fig. 2). By sequencing, it would be necessary to screen a large number of clones in order to find the same diversity.

To determine the possible species of origin of the detected rotavirus strains, we compared the RFLP profiles with those deduced from rotavirus sequences deposited in databases (Table 2). The RFLP profiles obtained from databases generally corresponded to rotaviruses from a single species (data not shown). Out of 49 RFLP profiles identified, 2 were obtained from viral sequences of different species (those showing similarities to profiles B and $\mathbf{J}$ in Table 2). Thus, it would appear that similarities between databases and experimental profiles can help specify the possible origin of rotaviruses. Five profiles obtained experimentally (profiles A, D, E, F, and K) were completely or partially homologous with profiles from human rotavirus sequences. The similarities found to sequences from human rotaviruses were not related to an imbalance in the number of human and animal viral sequences, since the same number of strains were compared (47 human and 46 animal rotavirus strains). Six RFLP profiles characterized in sewage treatment plant samples appeared to originate from animal (profiles $\mathrm{G}$ and $\mathrm{J}$ ) or both human and animal (profiles B, C, H, and I) rotavirus sequences. Normally, no animal waste entered the sewage treatment plant. Thus, all viral sequences should belong to human rotaviruses. However, there is increasing evidence of natural interspecies transmission of rotaviruses $(20,29)$. Sequences identified only in environmental samples might belong to animal rotaviruses causing human infections.

It may be concluded that RFLP analysis of the amplicons has demonstrated a variety of rotavirus dsRNAs in environmental samples and has shown a relationship between environmental contamination and human rotaviruses circulating in the population. This study indicates that effluent waters play a major role in strain dispersion in the environment. Moreover, the results obtained with treated effluent samples are more informative about the occurrence of rotavirus infections in the community than those obtained with raw sewage. Combination of RT-PCR and RFLP methods provides new comparative data on the presence of rotaviruses in environmental samples and offers an interesting approach for molecular epidemiological studies.

\section{ACKNOWLEDGMENTS}

We thank M. Le Berre and collaborators (Centre Hospitalier Regional, Saint Nazaire, France) for screening and providing rotaviruspositive stool samples from children, F. Galgani and F. Vincent (IFREMER, Nantes, France) for technical assistance for database analysis, and J. Cohen (INRA, Paris, France) and M. K. Estes (BCM, Houston, Tex.) for helpful advice and critical review of the manuscript.

This work was supported by a grant from the Conseil Régional des Pays de la Loire and IFREMER (France).

\section{REFERENCES}

1. Ansari, S. A., V. S. Springthorpe, and S. A. Sattar. 1991. Survival and vehicular spread of human rotaviruses: possible relation to seasonality of outbreaks. Rev. Infect. Dis. 13:448-461.

2. Beril, C., and L. Schwartzbrod. 1989. Détection des rotavirus dans les moules. Microbiol. Alim. Nutr. 7:175-182.

3. Bosch, A., R. M. Pinto, A. R. Blanch, and J. T. Jofre. 1988. Detection of human rotavirus in sewage through two concentration procedures. Water Res. 22:343-348.

4. Cook, S. M., R. I. Glass, C. W. LeBaron, and M. S. Ho. 1990. Global seasonality of rotavirus infections. Bull. W. H. O. 68:171-177.

5. De Leon, R., and C. P. Gerba. 1991. Detection of rotaviruses in water by gene probes. Water Sci. Technol. 44:281-284.

6. Dessen, P., C. Fondrat, C. Alencien, and C. Mugnier. 1990. Bisance: a French service for access to molecular sequence databases. Comput. Appl. Biosci. 6:355-356.

7. Estes, M. K., D. Y. Graham, and D. H. Dimitrov. 1984. The molecular epidemiology of rotavirus gastroenteritis. Prog. Med. Virol. 29:1-22.

8. Flores, J., J. Sears, I. Perez Schael, L. White, D. Garcia, C. Lanata, and A. Z Kapikian. 1990. Identification of human rotavirus serotype by hybridization to polymerase chain reaction-generated probes derived from a hyperdivergent region of the gene encoding outer capsid protein VP7. J. Virol. 64: 4021-4024.

9. Gajardo, R., N. Bouchriti, R. M. Pinto, and A. Bosch. 1995. Genotyping of rotaviruses isolated from sewage. Appl. Environ. Microbiol. 61:3460-3462.

10. Goswami, B. B., H. Koch, and T. A. Cebula. 1994. Competitor template RNA for detection and quantitation of hepatitis A virus by PCR. BioTechniques 16:114-121.

11. Gouvea, V., C. Ramirez, B. Li, N. Santos, L. Saif, H. F. Clark, and Y. Hoshino. 1993. Restriction endonuclease analysis of the vp7 genes of human and animal rotaviruses. J. Clin. Microbiol. 31:917-923.

12. Gouvea, V., R. I. Glass, P. Woods, K. Taniguchi, H. F. Clark, B. Forrester and Z.-Y. Fang. 1990. Polymerase chain reaction amplification and typing of rotavirus nucleic acid from stool specimens. J. Clin. Microbiol. 28:276-282.

13. Hejkal, T. W., E. M. Smith, and C. P. Gerba. 1984. Seasonal occurrence of rotavirus in sewage. Appl. Environ. Microbiol. 47:588-590.

14. Kapikian, A. Z., and R. M. Chanock. 1996. Rotaviruses, p. 1657-1708. In B. N. Fields, D. N. Knipe, P. M. Howley, R. M. Chanock, J. L. Melnick, T. P. Monath, B. Roizman, and S. E. Straus (ed.), Fields virology, 2nd ed., vol. 2. Raven Press, New York, N.Y.

15. Kopecka, H., S. Dubrou, J. Prevot, J. Marechal, and J. M. López-Pila. 1993. Detection of naturally occurring enteroviruses in waters by reverse transcription, polymerase chain reaction, and hybridization. Appl. Environ. Microbiol. 59:1213-1219.

16. Kristiansen, B.-E., B. Sørensen, T. Simonsen, O. Spanne. V. Lund, and B. Bjorvatn. Isolates of Neisseria meningitidis from different sites in the same patient: phenotypic and genomic studies, with special reference to adherence, piliation, and DNA restriction endonuclease pattern. J. Infect. Dis. 150:389-396.

17. Le Guyader, F., D. Menard, M. Pommepuy, and H. Kopecka. 1995. Use of RT seminested PCR to assess viral contamination in Caribbean rivers (Martinique). Water Sci. Technol. 31:391-394.

18. Le Guyader, F., E. Dubois, D. Menard, and M. Pommepuy. 1994. Detection of hepatitis A virus, rotavirus, and enterovirus in naturally contaminated shellfish and sediment by reverse transcription-seminested PCR. Appl. Environ. Microbiol. 60:3665-3671.

19. Mehnert, D. U., and K. E. Stewien. 1993. Detection and distribution of rotavirus in raw sewage and creeks in São Paulo, Brazil. Appl. Environ. Microbiol. 59:140-143.

20. Nakagomi, O., A. Ohshima, Y. Aboudy, I. Shif, M. Mochizuki, T. Nakagomi, and T. Gotlieb-Stematsky. 1990. Molecular identification by RNA-RNA hybridization of a human rotavirus that is closely related to rotaviruses of feline and canine origin. J. Clin. Microbiol. 28:1198-1203.

21. Noel, J. S., G. M. Beards, and W. D. Cubitt. 1991. Epidemiological survey of human rotavirus serotypes and electropherotypes in young children admitted to two children's hospitals in northeast London from 1984 to 1990. J. Clin. Microbiol. 29:2213-2219.

22. Pancorbo, O. C., B. G. Evanshen, W. F. Campbell, S. Lambert, S. K. Curtis, and T. W. Woolley. 1987. Infectivity and antigenicity reduction rates of human rotavirus strain Wa in fresh waters. Appl. Environ. Microbiol. 53: 1803-1811.

23. Pommepuy, M., A. Derrien, F. Le Guyader, D. Menard, M. P. Caprais, E. Dubois, E. Dupray, and M. Gourmelon. 1996. Microbial water quality on a Caribbean Island (Martinique). Coastal Estuarine Stud. 51:284-297.

24. Rao, V. C., T. G. Metcalf, and J. L. Melnick. 1988. Recovery of naturally occurring rotaviruses during sewage treatment. Virology 164:435-442.

25. Sambrook, J., E. F. Fritsch, and T. Maniatis. 1989. Molecular cloning: a laboratory manual, 2nd ed. Cold Spring Harbor Laboratory, Cold Spring Harbor, N.Y.

26. Smith, E. M., and C. P. Gerba. 1982. Development of a method for detection of human rotavirus in water and sewage. Appl. Environ. Microbiol. 43:1440 1450 . 
27. Sobsey, M. D. 1989. Inactivation of health-related microorganisms in water by disinfection processes. Water Sci. Technol. 21:179-195.

28. Tsai, Y.-L., B. Tran, L. R. Sangermano, and C. J. Palmer. 1994. Detection of poliovirus, hepatitis A virus, and rotavirus from sewage and ocean water by triplex reverse transcriptase PCR. Appl. Environ. Microbiol. 60:24002407.

29. Vonsover, A., I. Shif, I. Silberstein, H. Rudich, Y. Aboudy, E. Mendelson, L Shulman, T. Nakagomi, and O. Nakagomi. 1993. Identification of feline- and canine-like rotaviruses isolated from humans by restriction fragment length polymorphism assay. J. Clin. Microbiol. 31:1783-1787.

30. Ward, R. L., D. R. Knowlton, and P. E. Winston. 1986. Mechanism of inactivation of enteric viruses in fresh water. Appl. Environ. Microbiol. 52:450-459.

31. Zhou, Y.-J., M. K. Estes, X. Jiang, and T. G. Metcalf. 1991. Concentration and detection of hepatitis A virus and rotavirus from shellfish by hybridization tests. Appl. Environ. Microbiol. 57:2963-2968. 